\title{
Measurement and Quantitative Representation of Liquid-liquid Equilibria of Polystyrene-cyclopentane Systems
}

\author{
Yoshio Iwai ${ }^{\dagger 1)}$, Shuji Matsurama ${ }^{\dagger 1)}$, Yuji Shigematsu ${ }^{\dagger 1)}$, Yasuhiko Arai ${ }^{\dagger 1)}$, \\ Keiji Tamura $^{\dagger 2)}$, and Takeo Shiojima ${ }^{\dagger 2)}$ \\ †1) Department of Chemical Engineering, Kyushu University, \\ 6-10-1 Hakozaki, Higashi-ku, Fukuoka 812 \\ 12) Chiba Works, Idemitsu Petrochemical Co., Ltd., \\ 1-1 Anesaki Kaigan, Ichihara, Chiba 299-0 I
}

A quantitative equation which describes liquidliquid equilibria of polymer solutions is desired for process designs of polymer and related industries. The chemical potential equation proposed by Flory et al. is widely adopted for calculating the phase equilibria of polymer solutions. However, it sometimes dose not provide an adequately quantitative representation of the liquid-liquid equilibria of the systems consisting of a low molecular weight solvent and polymer.

Solubility curves of polystyrene-cyclopentane systems were obtained by observing the cloud points. Molecular weights of the six polymer samples used are shown in Table 1. The cloud points shown in Fig. 1 were determined by detecting the rapid change in the light transmittance of the polymer solutions contained in a highpressure glass cell. In Fig. 2, the Shultz-Flory plot is shown for the upper critical solution temperature (UCST) as a function of segment number of polystyrene. The cloud points obtained in this work seem to be reliable because the relationship between UCST and the segment number for the present data agrees well with that of literature ${ }^{1)}$.

It was found empirically that the interaction parameter between solvent molecule and polymer segment seemed to be a function of temperature, molecular weight, and volume fraction of polystyrene as expressed by Eq. (2) to give the good correlations of the liquid-liquid equilibria of the present systems. Using the parameters listed in Tables 2 and 3, a successful representation is obtained by modified Flory equations, i.e., Eqs. (3) and (4) as illustrated in Fig. 1.

\section{Keywords}

Cloud point, Liquid liquid equilibrium, Critical solution temperature, Polystyrene, Cyclopentane, Modified Flory equation

訂

正

本誌第 32 巻第 6 号に下記の䛊りがありましたので, 訂正いたします。

319 頁 4 行目

Shin-ichi Nagano（誤)

Shinichi Nagano (正)

\section{ERRATUM}

Vol. 32 No. 6 p. 319 L. 4

"Catalytic Activity and Selectivity of Potassium-Promoted

Ultrafine Particles of Iron for Liquid Phase Fisher-Tropsch Synthesis"

We regret that "Shin-ichi NAgano" should have been printed as "Shinichi NAGANO". 